\title{
Computational Studies on the Mechanisms for Deaminative Amide Hydrogenation by Homogeneous Bifunctional Catalysts
}

\author{
Lluís Artús Suàrez ${ }^{1} \cdot$ David Balcells $^{1} \cdot$ Ainara Nova ${ }^{1,2}$ (]) \\ Accepted: 17 November 2021 / Published online: 14 December 2021 \\ (c) The Author(s) 2021
}

\begin{abstract}
The deaminative hydrogenation of amides is one of the most convenient pathways for the synthesis of amines and alcohols. The ideal source of reducing equivalents for this reaction is molecular hydrogen, though, in practice, this approach requires high pressures and temperatures, with many catalysts achieving only small turnover numbers and frequencies. Nonetheless, during the last ten years, this field has made major advances towards larger turnovers under milder conditions thanks to the development of bifunctional catalysts. These systems promote the heterolytic cleavage of hydrogen into proton and hydride by combining a basic ligand with an acidic metal centre. The present review focuses on the computational study of the reaction mechanism underlying bifunctional catalysis. This review is structured around the fundamental steps of this mechanism, namely the $\mathrm{C}=\mathrm{O}$ and $\mathrm{C}-\mathrm{N}$ hydrogenation of the amide, the $\mathrm{C}-\mathrm{N}$ protonolysis of the hemiaminal, the $\mathrm{C}=\mathrm{O}$ hydrogenation of the aldehyde, and the competition between hydrogen activation and catalyst deactivation. In line with the complexity of the mechanism, we also provide a perspective on the use of microkinetic models. Both Noyori- and Milstein-type catalysts are discussed and compared.
\end{abstract}

Keywords Reaction mechanisms $\cdot$ Hydrogenation $\cdot$ Amides $\cdot$ Computational study

\section{Introduction}

Amides are the most thermodynamically stable and kinetically inert species of the carboxylic acid derivatives, mainly because the polarity of their carbonyl group is the lowest in the series shown in Fig. 1. Nonetheless, amides play prominent roles in biochemistry, in the synthesis of industrial and fine chemicals [1-6], and in the conversion of $\mathrm{CO}_{2}$ to methanol [7-10]. In addition, amides could be ideal precursors for the synthesis of amines, imines, aldehydes or alcohols, due to their natural abundance and industrial accessibility. However, efficient and cheap protocols for amide hydrogenation remain scarce.

Ainara Nova

ainara.nova@kjemi.uio.no

1 Department of Chemistry, Hylleraas Centre for Quantum Molecular Sciences and Centre for Materials Science and Nanotechnology, University of Oslo, Blindern, P.O. Box 1033, 0315 Oslo, Norway

2 Department of Chemistry, Hylleraas Centre for Quantum Molecular Sciences, UiT-The Arctic University of Norway, 9037 Troms $\varnothing$, Norway
Traditional methods for amide reduction relied either on heterogeneous catalysts or on the consumption of stoichiometric amounts of strong reducing agents, such as $\mathrm{LiAlH}_{4}$ or $\mathrm{LiBH}_{4}$ [11-14]. Unfortunately, these methods had only partial control over the regioselectivity, produced chemical waste and/or needed harsh reaction conditions (>100 atm). Initial attempts towards the deaminative hydrogenation of amides to alcohols using an homogeneous catalyst and molecular hydrogen were documented in 2003 within a patent [15]. The catalyst was a ruthenium dihydride carbonyl complex supported by the triphos ligand, $[\mathrm{Ru}$ (triphos) $\left.\mathrm{CO}(\mathrm{H})_{2}\right]$. However, ruthenium is a precious metal, and the reaction required high temperatures and pressures, achieving only a modest turn over number (TON) and turn over frequency (TOF) of 600 and $43 \mathrm{~h}^{-1}$, respectively. Seven years later, in 2010, the Milstein group used for the first time a bifunctional catalyst for this reaction, drastically reducing the temperature and pressure conditions from $68 \mathrm{~atm}$ and $164{ }^{\circ} \mathrm{C}$ to $10 \mathrm{~atm}$ and $110^{\circ} \mathrm{C}$ [16]. From then onward, bifunctional catalysts gained popularity and rapidly dominated the homogeneous catalysis of deaminative hydrogenation of amides to alcohols [17, 18]. 


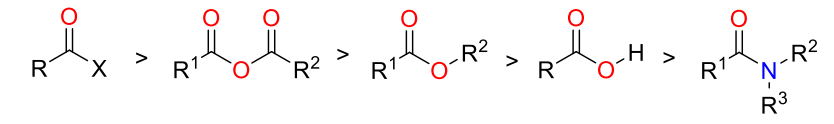

acyl halide acid anhydride ester carboxylic acid amide

Most reactive

Most polar

Least reactive Least polar

Fig. 1 Relative reactivity and polarity of carboxylic acid derivatives. $\mathrm{X}=$ halide

Bifunctional catalysts for hydrogenation reactions are typically organometallic species that contain a ligand with a weak base atom near a metallic centre (see Fig. 2) [19-22]. That characteristic allows them to reversibly and heterolytically break hydrogen molecules into hydrides and protons, thus promoting hydrogenation reactions. Within these catalysts, we can differentiate two prominent families, depending on the basic atom of their ligands: Noyori-type catalysts, where the ligand basic centre is a nitrogen directly bound to the metal; and Milstein-type catalysts, where the basic centre is a $\mathrm{C}(\mathrm{H})$ in the orto position of a pyridine ring.

Several reviews have been published on the hydrogenation of ketones, esters and amides, with bifunctional catalysts $[17,20,22,23]$. However, in this review, we have focused on the reaction mechanisms for the deaminative hydrogenation of amides using molecular hydrogen. Although we include experimental work, the main focus is on computational studies exploring different mechanisms.

This review is organized in Sections describing the mechanisms that have been proposed for the different steps of the reaction (see Fig. 3). These steps are the following: amide
$\mathrm{C}=\mathrm{O}$ hydrogenation $($ Sect. 2 ) or, alternatively, amide $\mathrm{C}-\mathrm{N}$ hydrogenation (Sect. 3), hemiaminal C-N bond protonolysis (Sect. 4), aldehyde $\mathrm{C}=\mathrm{O}$ hydrogenation (Sect. 5), and the hydrogenation of the catalyst (i.e. catalyst recovery), which has been described together with catalyst deactivation in Sect. 6. Since the deaminative hydrogenation of amides is a multistep process, a final section has been added to discuss the use of microkinetic models (Sect. 7) [24-27].

\section{Reaction Mechanisms for Amide $\mathrm{C}=\mathrm{O}$ Hydrogenation}

The first step for amide hydrogenation is the hydrogenation of its carbonyl group. For this step, the proposed mechanism is the same as for the hydrogenation of other carbonyl groups such as esters, ketones and aldehydes [28]. This mechanism starts with a hydride transfer from the catalyst to the carbon of the carbonyl group, followed by the protonation of the negatively charged $\mathrm{O}$ of the carbonyl group via an outer sphere mechanism [29-31]. A first protonation pathway has been proposed only in highly nucleophilic substrates, e.g. quinolines or acridines [32]. In the $\mathrm{C}=\mathrm{O}$ hydrogenation of ketones to alcohols, two different mechanisms have been proposed depending on whether the proton source is the catalyst ligand or the hydrogen molecule (see Fig. 4) [19, 20]. These mechanisms are sometimes referred to as non-innocent and innocent ligand carbonyl hydrogenation, respectively. However the later mechanism has not been reported as the preferred one with amides. In addition, calculations performed by our group with an iron-based Noyori-type
Fig. 2 Examples of Noyori- and Milstein-type catalysts activations (orange) and inhibitions (dark blue). Most frequent metallic centres $(\mathrm{M})$ are $\mathrm{Ru}, \mathrm{Fe}$ or Mn. Most frequent X-H molecules: formanilide, methanol or ethanol. Dashed lines indicate that there is not a bond connecting the transition metal centre and the nucleophilic centre. $\mathrm{Y}=\mathrm{H}$ or $\mathrm{CO}$

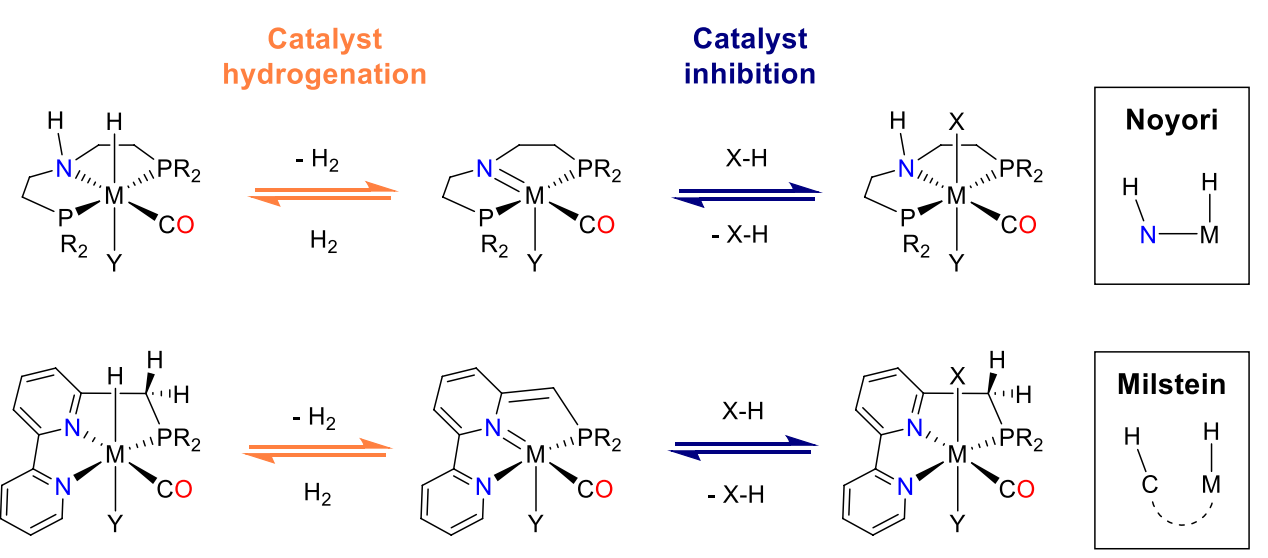

\section{inhibition}

Fig. 3 Main pathways for amide hydrogenation to alcohols and amines with bi-functional Noyori-type catalysts

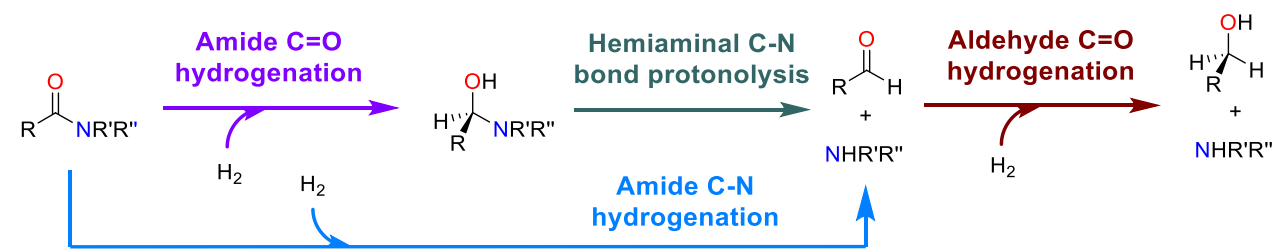


Fig. 4 Mechanisms proposed for the hydrogenation of carbonyl groups assisted by organometallic complexes

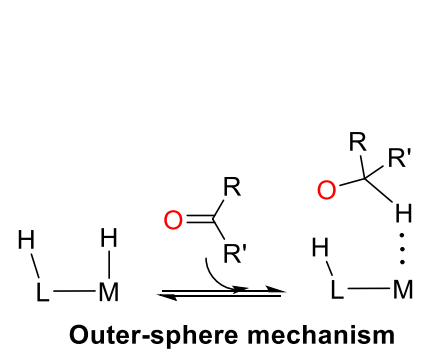

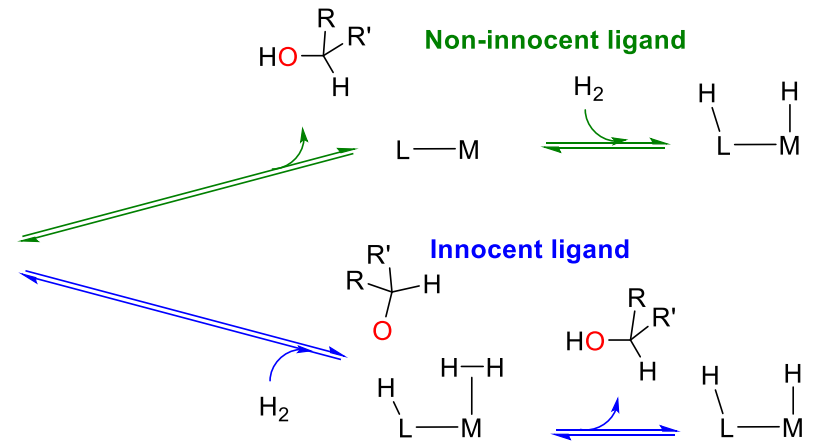

catalyst and a hydrogen molecule as proton source, showed that this path is $13.7 \mathrm{kcal} \mathrm{mol}^{-1}$ more energetic than the non-innocent path.

Regarding the Milstein-type catalysts, the first computational study for an amide hydrogenation reaction using DFT calculations was published in 2014 by Hasanayn and Harab (see Fig. 5) [33]. The reaction mechanism starts with an outer-sphere hydride transfer from the metal to the amide carbonyl carbon $\left(\mathrm{TS}=27.5 \mathrm{kcal} \mathrm{mol}^{-1}\right)$, followed by a proton transfer from the acidic orto- $\mathrm{CH}_{2}$ of the ligand to the amide carbonyl oxygen $\left(28.3 \mathrm{kcal} \mathrm{mol}^{-1}\right)$ yielding the corresponding hemiaminal. One year later, in 2015, Zhang explored the mechanism of Hasanayn and Harab with a catalyst derivative replacing the $\mathrm{NEt}_{2}$ group by a pyridine ring, which reduced the barrier of the rate-limiting step by $2.5 \mathrm{kcal} \mathrm{mol}^{-1}$ (see Fig. 5) [29]. Remarkably, this ligand modification also reduced the energy barrier of the hydride transfer by more than $10 \mathrm{kcal} \mathrm{mol}^{-1}$. The study of Zhang also explored the alternative pathway for the $\mathrm{C}-\mathrm{N}$ hydrogenation of the amide (see Sect. 3), which was found to be $10 \mathrm{kcal} \mathrm{mol}^{-1}$ more energetic than the $\mathrm{C}=\mathrm{O}$ hydrogenation pathway.

Concerning Noyori-type catalysts, a summary of the energies reported for the amide $\mathrm{C}=\mathrm{O}$ hydrogenations with $\mathrm{Fe}$, $\mathrm{Mn}, \mathrm{Ru}$ and Mo complexes and different amide substrates is shown in Figs. 6 and 7 [24, 26, 27, 34]. The hydrogenation of formanilide, morpholidine and dimethylformamide (DMF) by an iron Noyori-type catalyst was studied by our group in 2018 (see Fig. 6) [24, 27]. In this study, it was found that all transition states were thermally accessible, and that the formation of most intermediates and products was endergonic. The proton transfer yielded the highest TS for formanilide and DMF but not for morpholidine. Nevertheless, in this case the energies of the two TSs and the zwitterion intermediate were similar. Protonation steps with high energy barriers were also found for Ru and Mn systems in later studies performed by Pathak et al. [34] However for $\mathrm{Mn}$ and $\mathrm{Ru}$, the differences between the protonation and hydride transfer TSs were larger; 2.0 and $6.0 \mathrm{kcal} \mathrm{mol}^{-1}$,

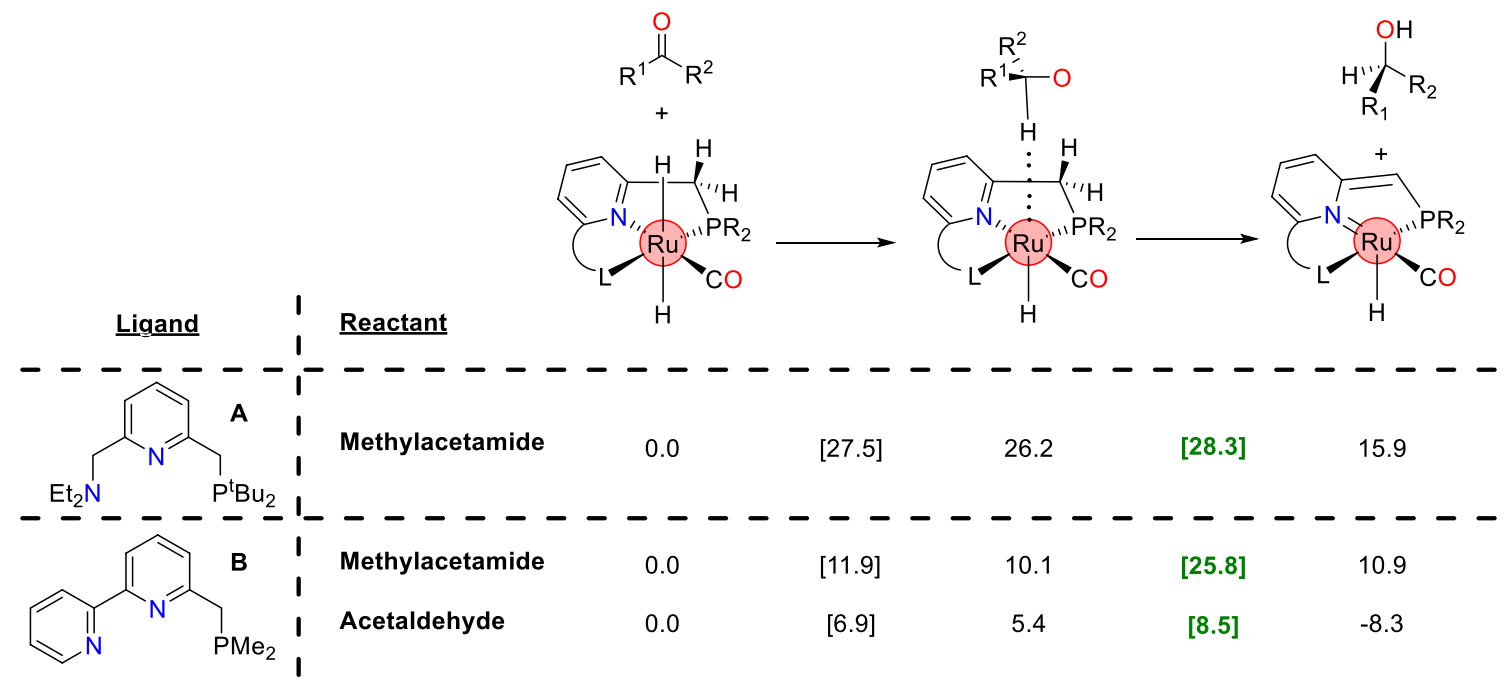

Fig. 5 Examples of reaction mechanism of $\mathrm{C}=\mathrm{O}$ hydrogenations with bifunctional Milstein-type catalysts [29]. Methods: (Ligand A) M06L, 6-311++G(2d,2p) Hay-Wadt 3-x, SMD=Toluene, $\mathrm{T}=298 \mathrm{~K}, \mathrm{P}=1 \mathrm{~atm}$ (Ligand B) B3LYP, 6-311++G(d,p) LAN-
L2DZ, IEFPCM=THF, T=298.15 K, P=1 atm. The tert-butyl in B ligand was simplified to methyl to ease computation. Gibbs energies in $\mathrm{kcal} \mathrm{mol}^{-1}$ 


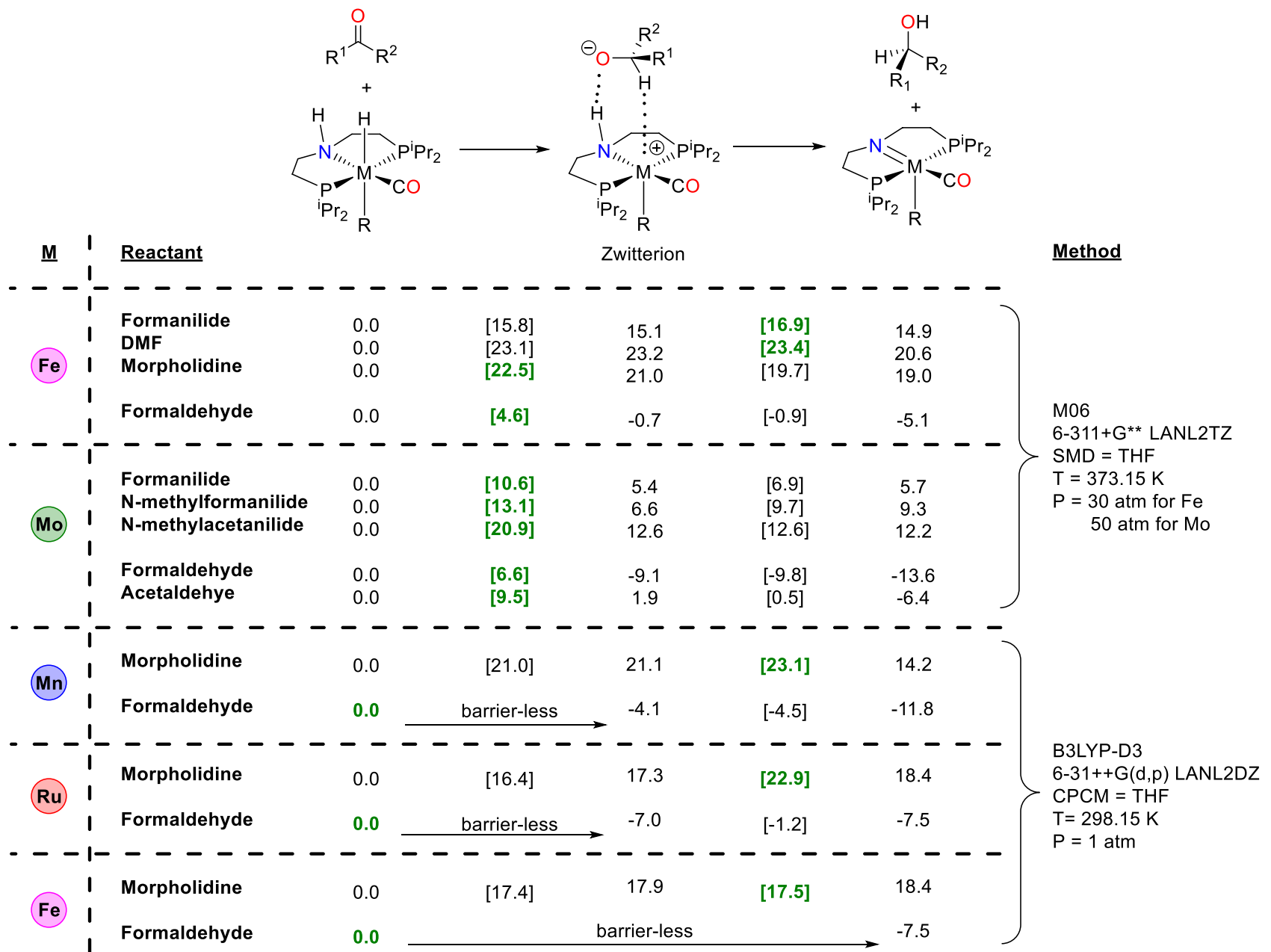

Fig. 6 Examples of reaction mechanisms for the $\mathrm{C}=\mathrm{O}$ hydrogenation of different amides with bifunctional Noyori-type catalysts [24, 26, 27, 34]. $\mathrm{R}=\mathrm{CO}$ for $\mathrm{M}=\mathrm{Mo}$ and $\mathrm{Mn} . \mathrm{R}=\mathrm{H}$ for $\mathrm{Fe}$ and $\mathrm{Ru}$. Gibbs energies in $\mathrm{kcal} \mathrm{mol}^{-1}$

Fig. 7 Example of reaction mechanism of $\mathrm{C}=\mathrm{O}$ hydrogenations with a Noyori-type catalysts [36]. Gibbs energies in $\mathrm{kcal} \mathrm{mol}^{-1}$

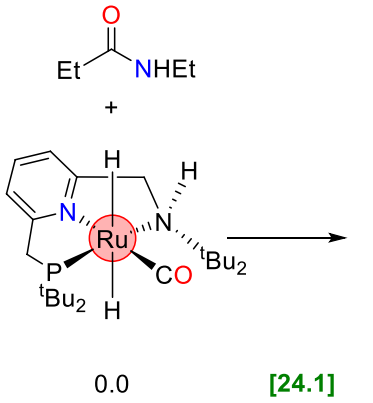

respectively. In addition, the energy barriers increased in the order $\mathrm{Fe}<\mathrm{Ru}<\mathrm{Mn}$.

In the case of Mo [26], the hydride transfer has a higher energy barrier than the protonation but a lower barrier than the same process with $\mathrm{Mn}, \mathrm{Fe}$ and Ru. However, the lower barrier cannot be directly related with milder conditions for amide hydrogenation with Mo because it forms highly

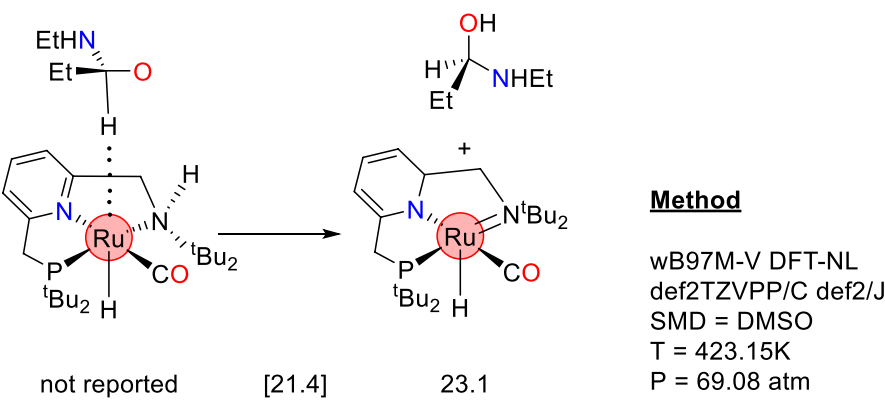

stable adducts with the resulting alcohols that hinder catalyst recovery (see Sect. 6).

In 2020, the Milstein group reported a Ru catalyst containing both the Milstein and the Noyori moieties (see Fig. 7) [36]. The study concluded that amide $\mathrm{C}=\mathrm{O}$ hydrogenation proceeds through the Noyori active site, with the hydride transfer step yielding the highest energy barrier. 


\section{Reaction Mechanisms for Amide C-N Hydrogenation}

Reaction mechanisms for the hydrogenation of the amide $\mathrm{C}-\mathrm{N}$ bond have been explored by several groups as a potential pathway competing with amide $\mathrm{C}=\mathrm{O}$ hydrogenation and hemiaminal $\mathrm{C}-\mathrm{N}$ protonolysis. However, in the systems in which these mechanisms have been computed and compared, C-N hydrogenation was disfavored by high-energy pathways.

In 2011, Cantillo reported the hydrogenation of the $\mathrm{N}$-Ethylacetamide $\mathrm{C}-\mathrm{N}$ bond with a Milstein-type catalyst via an inner-sphere mechanism [30] involving three steps: (1) amide coordination to the metal centre, (2) insertion of the amide carbonyl into the catalyst metal-hydride bond, and (3) concerted protonation of the amide $\mathrm{N}$ and cleavage of the $\mathrm{C}-\mathrm{N}$ bond (see Fig. 8). The rate-limiting step of this mechanism was the insertion of the amide carbonyl, which was not thermally accessible. Four years later, Zhang reported the same mechanism with N-Methylacetamide (see Fig. 8) [19]. Importantly, this study showed that the amide C-N hydrogenation pathway was $9.9 \mathrm{kcal} \mathrm{mol}^{-1}$ higher in energy than that combining the amide $\mathrm{C}=\mathrm{O}$ hydrogenation with the hemiaminal $\mathrm{C}-\mathrm{N}$ protonolysis.

In 2019, Pathak et al. published an outer-sphere variation of the mechanism published by Cantillo, with $\mathrm{Ru}, \mathrm{Fe}$ and Mn Noyori-type catalysts (see Fig. 9) [34, 35]. In Pathak's study, the amide coordination and carbonyl insertion steps were replaced by a single step transferring the hydride from the metal centre to the amide carbonyl. The steps with the higher energy barriers were the amide $\mathrm{N}$ protonation and $\mathrm{C}-\mathrm{N}$ cleavage. This mechanism involved lower energies than those reported by Cantillo and Zhang for inner-sphere mechanism, though they were not thermally accessible either.

In 2020, Milstein et al. explored an outer-sphere mechanism with a $\mathrm{C}-\mathrm{N}$ bond rotation $\mathrm{TS}$ to create a $\mathrm{Ru}-\mathrm{O}$ bond (see Fig. 10). This interaction stabilized the $\mathrm{C}-\mathrm{N}$ cleavage TS in a mechanism in which the rotation step involved the highest energy barrier [33, 36]. Nonetheless, the amide $\mathrm{C}-\mathrm{N}$ hydrogenation pathway was more energetic than the alternative mechanism involving $\mathrm{C}=\mathrm{O}$ hydrogenation followed by the $\mathrm{C}-\mathrm{N}$ cleavage of the hemiaminal.

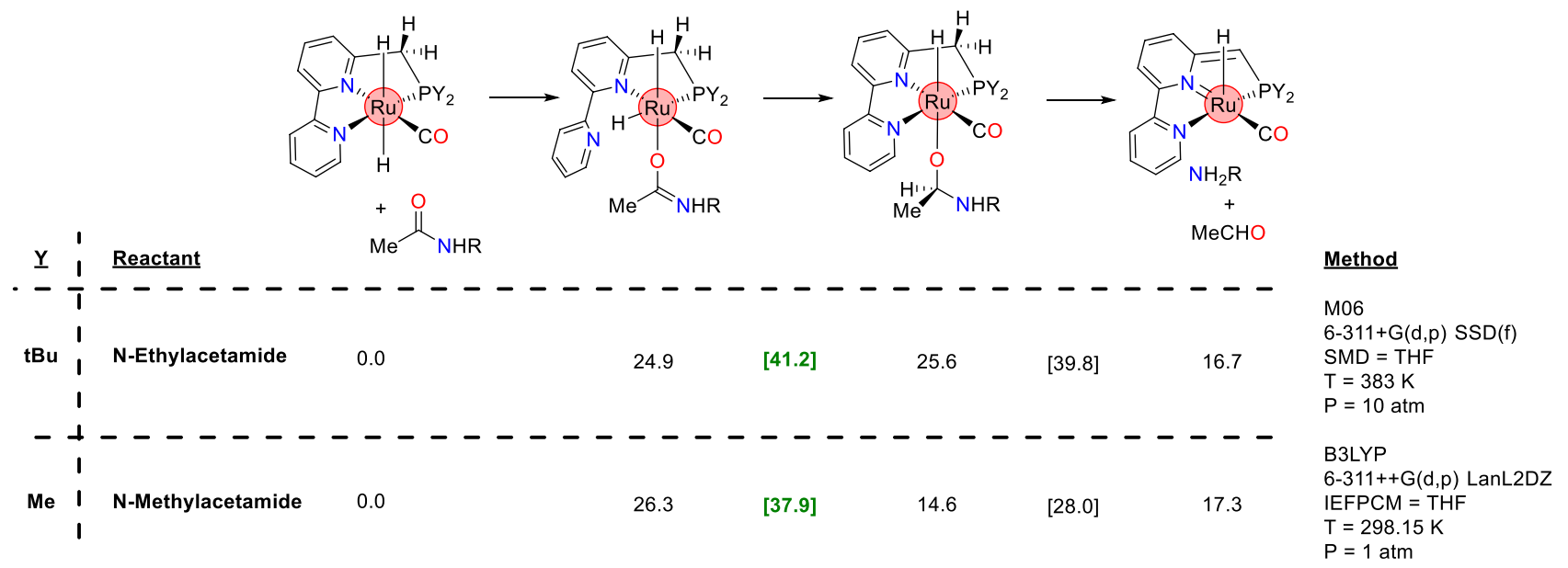

Fig. 8 Examples of reaction mechanism of amide C-N hydrogenation with Milstein-type catalysts [29, 30]. Gibbs energies in kcal mol ${ }^{-1}$. In $\mathrm{Y}=\mathrm{Me}$, the tert-butyl substituent of the ligand was simplified to methyl to ease computation

Fig. 9 Examples of reaction mechanism of $\mathrm{C}=\mathrm{N}$ hydrogenations with bifunctional Noyoritype catalysts [34]. $\mathrm{R}=\mathrm{CO}$ for $\mathrm{M}=\mathrm{Mn} . \mathrm{R}=\mathrm{H}$ for $\mathrm{Fe}$ and $\mathrm{Ru}$. Gibbs energies in $\mathrm{kcal} \mathrm{mol}^{-1}$

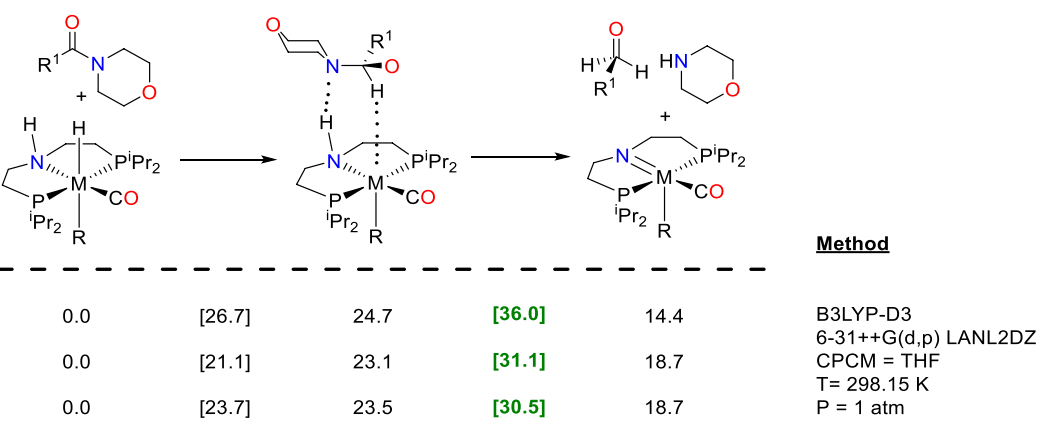




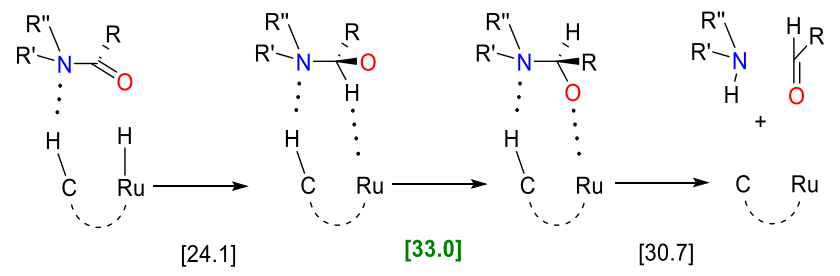

Fig. 10 Milstein proposed mechanisms for amide $\mathrm{C}-\mathrm{N}$ hydrogenation $[33,36]$. Gibbs energies in $\mathrm{kcal} \mathrm{mol}^{-1}$. Amide + hydrogenated catalyst $=0 \mathrm{kcal} \mathrm{mol}^{-1}$

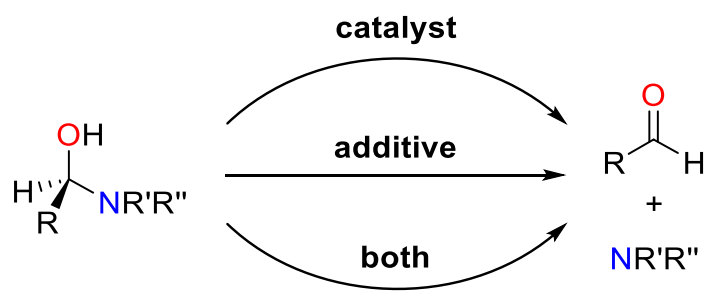

Fig. 11 Division of hemiaminal C-N protonolysis mechanisms

\section{Reaction Mechanisms for Hemiaminal C-N Protonolysis}

In contrast with the reaction mechanisms for $\mathrm{C}=\mathrm{O}$ hydrogenation by bifunctional catalysts, there is no consensus on how these catalysts promote the $\mathrm{C}-\mathrm{N}$ bond protonolysis of the hemiaminal intermediate, which appears to be substrate- and catalyst-dependent. In addition, it has been reported that secondary amides, alcohols and other slightly acidic molecules can be involved in the mechanisms of $\mathrm{C}-\mathrm{N}$ bond protonolysis [37-43]. Therefore, we classified these reaction mechanisms in three different categories: (1) catalyst-assisted, (2) additive-assisted, and (3) assisted by both catalyst and additive (see Fig. 11).

\subsection{Assisted by the Organometallic Catalyst}

There are two main reaction pathways reported in the literature for the protonolysis of the hemiaminal $\mathrm{C}-\mathrm{N}$ bond solely assisted by the organometallic catalysts. The first mechanism consists of the coordination of the amide nitrogen to the metallic centre and the deprotonation of the hemiaminal $\mathrm{OH}$ group by the catalyst ligand, followed by $\mathrm{C}-\mathrm{N}$ cleavage yielding an aldehyde and a metal-bound amido ligand, which, in the last step, is transformed into the amine product by intramolecular protonation (see Figs. 12 and 13). The reduction of the aldehyde to the alcohol product is crucial for the thermodynamic balance of the overall reaction. Hasanayn and Harb reported this pathway in 2014 for the hemiaminal $\mathrm{C}-\mathrm{N}$ protonolysis of methylacetamide with ruthenium Milstein-type catalyst, with the highest energy barrier being at $24.7 \mathrm{kcal} \mathrm{mol}^{-1}$ for the first step (see Fig. 12) [33]. Later in 2018 and 2019, our group found that this mechanism is also the most favourable for the hemiaminal $\mathrm{C}-\mathrm{N}$ protonolysis of formanilide, $\mathrm{N}$-methylformanilide and $\mathrm{N}$-methylacetanilide when catalyzed by iron or molybdenum Noyori-type catalysts, in the absence of additivies acting as proton shuttle (see Fig. 13) [24, 26, 27]. In these systems, the $\mathrm{C}-\mathrm{N}$ bond cleavage was the rate-limiting step, with energy barriers up to $24.9 \mathrm{kcal} \mathrm{mol}^{-1}$. However, $\mathrm{N}$-methylformanilide and $\mathrm{N}$-methylacetanilide can benefit from a later alcohol formation, which will open less energetic reaction mechanisms catalyzed both by the organometallic catalysts and alcohol as a proton shuttle (see Sect. 4.3).

The second reaction mechanism (see Fig. 14) also starts with the deprotonation of the hemiaminal $\mathrm{OH}$ by the catalyst ligand, but in this case, it is the hemiaminal oxygen that binds to the metal centre instead of the nitrogen. Then, a concerted hydrogen transfer from the ligand to the hemiaminal nitrogen occurs, together with a $\mathrm{C}-\mathrm{N}$ bond cleavage, forming a molecule of aldehyde and amine. In 2015, Zhang reported that the hemiaminal $\mathrm{C}-\mathrm{N}$ protonolysis of methylacetamide by ruthenium Milstein-type catalysts followed this mechanism with a maximum energy barrier of

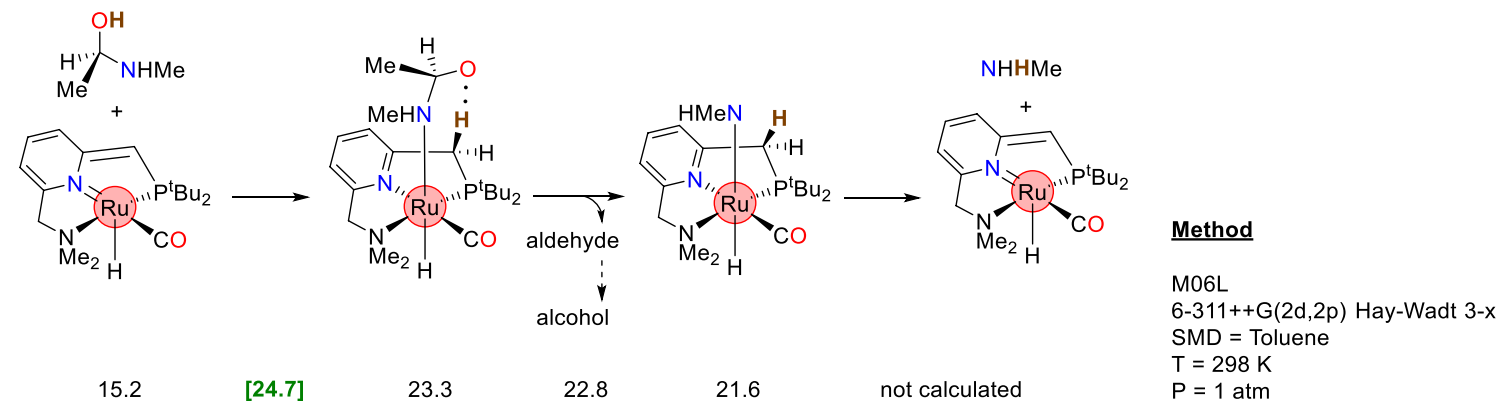

Fig. 12 Example of reaction mechanism of hemiaminal C-N protonolysis with Milstein-type catalysts via N-metal bond formation [33]. Gibbs energies in $\mathrm{kcal} \mathrm{mol}^{-1}$. Amide + hydrogenated catalyst $=0 \mathrm{kcal} \mathrm{mol}^{-1}$ 


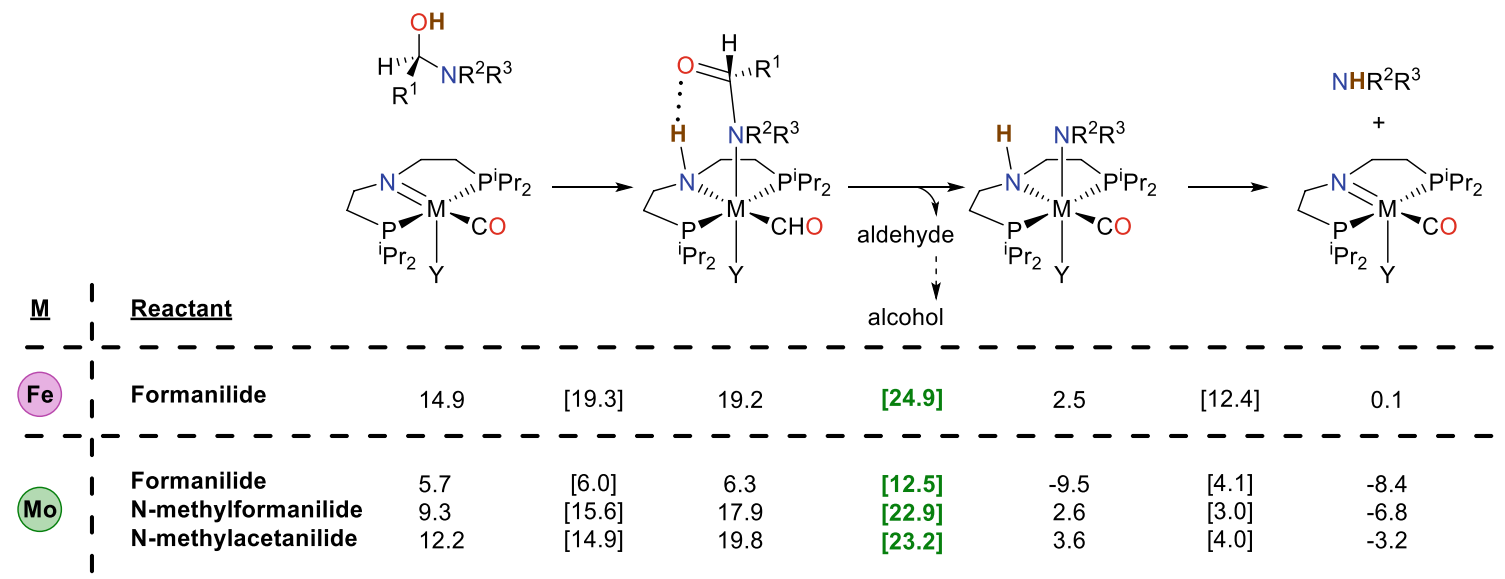

Fig. 13 Example of reaction mechanism of hemiaminal $\mathrm{C}-\mathrm{N}$ protonolysis with Noyori-type catalysts via O-metal bond [24, 26, 27]. $\mathrm{Y}=\mathrm{H}$ for $\mathrm{M}=\mathrm{Fe} . \mathrm{Y}=\mathrm{CO}$ for $\mathrm{M}=\mathrm{Fe} . \mathrm{M} 06,6-311+\mathrm{G}^{* *} \mathrm{LANL2TZ}$,

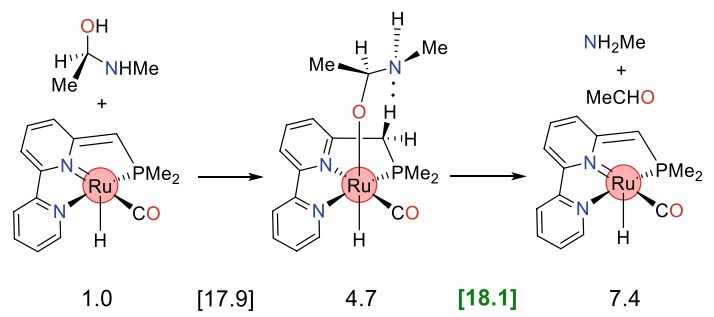

Fig. 14 Example of reaction mechanism of hemiaminal C-N protonolysis with Milstein-type catalysts via O-metal bond [29]. B3LYP, 6-311++G(d,p) LANL2DZ, IEFPCM=THF, T=298.15 K, $\mathrm{P}=1 \mathrm{~atm}$. Gibbs energies in $\mathrm{kcal} \mathrm{mol}^{-1}$. Amide + hydrogenated catalyst $=0 \mathrm{kcal} \mathrm{mol}^{-1}$

$18.1 \mathrm{kcal} \mathrm{mol}^{-1}$ associated with the $\mathrm{C}-\mathrm{N}$ bond cleavage [29]. Higher energy profiles were found for other Milstein systems [36]. This mechanism was also calculated with Noyori-type catalysts, though it was more energetic than other mechanisms previously reported in the literature [24, 26, 27].
$\mathrm{SMD}=\mathrm{THF}, \mathrm{T}=373.15 \mathrm{~K}, \mathrm{P}=30 \mathrm{~atm}$ for $\mathrm{Fe}, 50 \mathrm{~atm}$ for Mo. Gibbs energies in $\mathrm{kcal} \mathrm{mol}^{-1}$. Amide + hydrogenated catalyst + proton shuttle $=0 \mathrm{kcal} \mathrm{mol}^{-1}$

\subsection{Assisted by a Proton Shuttle Molecule}

In 2016, the Sanford group, observed higher conversions of unreactive amides in the presence of catalytic quantities of weak bases such as $\mathrm{K}_{3} \mathrm{PO}_{4}$ or $\mathrm{NEt}_{3}$ [44]. One year later, Hazari and Bernskoetter, found similar results but with weak acids such as formanilide derivatives or aniline [37-43]. In 2018, computational studies showed that the co-catalytic activity of secondary amides was due to their low acidity, which allowed for assisting the intramolecular proton transfer from the hemiaminal nitrogen to the oxygen (see Fig. 15), reducing the associated energy barriers by more than $10 \mathrm{kcal} \mathrm{mol}^{-1}$. On the other hand, methanol, which is produced during the deaminative hydrogenation of amides, was shown to catalyze $\mathrm{C}-\mathrm{N}$ protonolysis [24-26]. In this case, the hemiaminal $\mathrm{OH}$ deprotonation and $\mathrm{N}$ protonation occured in a single concerted step. This mechanism has a catalytic effect but it is less important than that of the amides, since it involves a transition state that is higher in

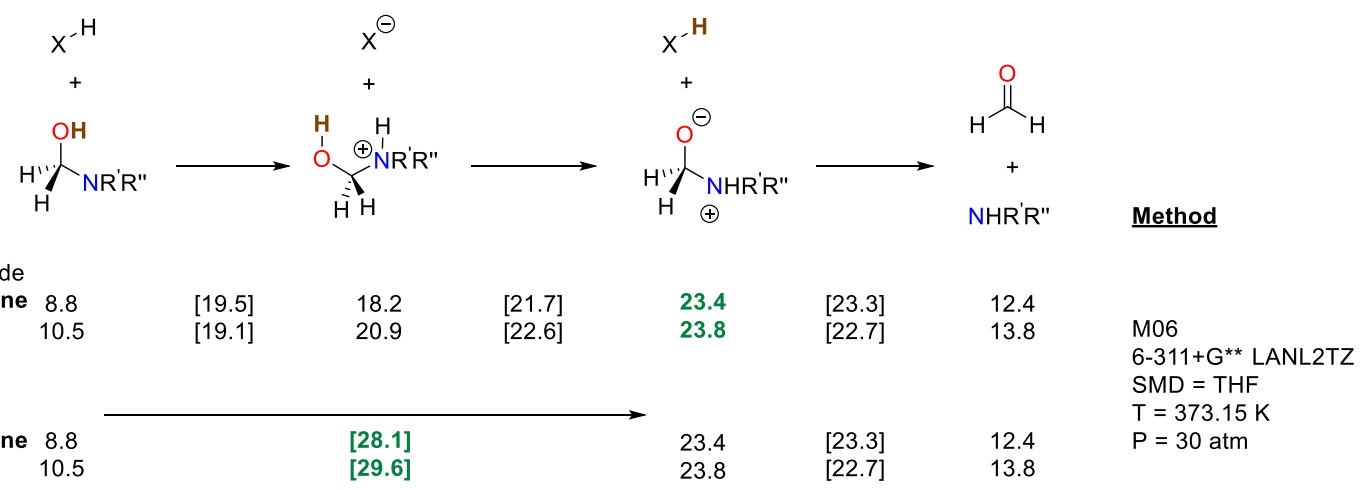

Fig. 15 Example of reaction mechanism of hemiaminal $\mathrm{C}-\mathrm{N}$ protonolysis hydrogenations with most effective tested proton-shuttle molecules $[24,25,27]$. Gibbs energies in kcal mol ${ }^{-1}$. Amide $+\mathrm{H}_{2}+$ proton shuttle $=0 \mathrm{kcal} \mathrm{mol}^{-1}$ 
energy by $\sim 5 \mathrm{kcal} \mathrm{mol}^{-1}$. Nonetheless, the co-catalytic effect of methanol can be relevant at high concentrations.

The use of alcohols and secondary amides as co-catalyst was proven to have three relevant drawbacks: (1) they can poison Noyori-type catalysts by blocking the active site (see Sect. 6), (2) secondary amides are gradually hydrogenated at the same time as the substrate, thereby loosing their catalytic properties, and (3) several alcohols do not reduce the energy barriers by a significant extent. After considering these drawbacks, in 2020, our group performed a computational catalyst optimization to find proton shuttle molecules that neither block the active site of the catalyst nor be hydrogenated by it [25]. The calculations identified triazabicyclodecene (TBD) as an efficient proton shuttle for this reaction (see Fig. 16). The co-catalytic effect of TBD is based on the reaction mechanism depicted in Fig. 16, which yielded the lowest-energy transition states among all proton transfer reactions presented in this review. Additionally, TBD did not poison the catalyst (see Sect. 6) and co-catalyzed the deaminative hydrogenation of a broad spectrum of amides.

\subsection{Assisted by an Organometallic Catalyst and a Proton Shuttle Molecule}

Some proton shuttle molecules have been found to cooperate with bifunctional catalysts to promote hemiaminal C-N protonolysis. One case is methanol, which after binding to a dehydrogenated molybdenum Noyori-type catalysts, can promote the protonation of some hemiaminals (see Fig. 17) [26]. This mechanism is especially relevant for molybdenum Noyori-type catalysts due to the strong interaction of methanol with this type of catalysts. Despite a major reduction of the energy barrier by $20 \mathrm{kcal} \mathrm{mol}^{-1}, \mathrm{C}-\mathrm{N}$ protonolysis remains as the rate-limiting step of the hydrogenation of formanilide with molybdenum Noyori-type catalysts.

A similar case is that of dihydrogen (see Fig. 17), which can bind to an iron dehydrogenated Noyori-type catalyst to catalyze $\mathrm{C}-\mathrm{N}$ protonolysis following the same mechanism described for methanol and molybdenum. Because of the high-energy transition states present in this mechanism $\left(>30 \mathrm{kcal} \mathrm{mol}^{-1}\right)$, it is the rate-limiting step of the

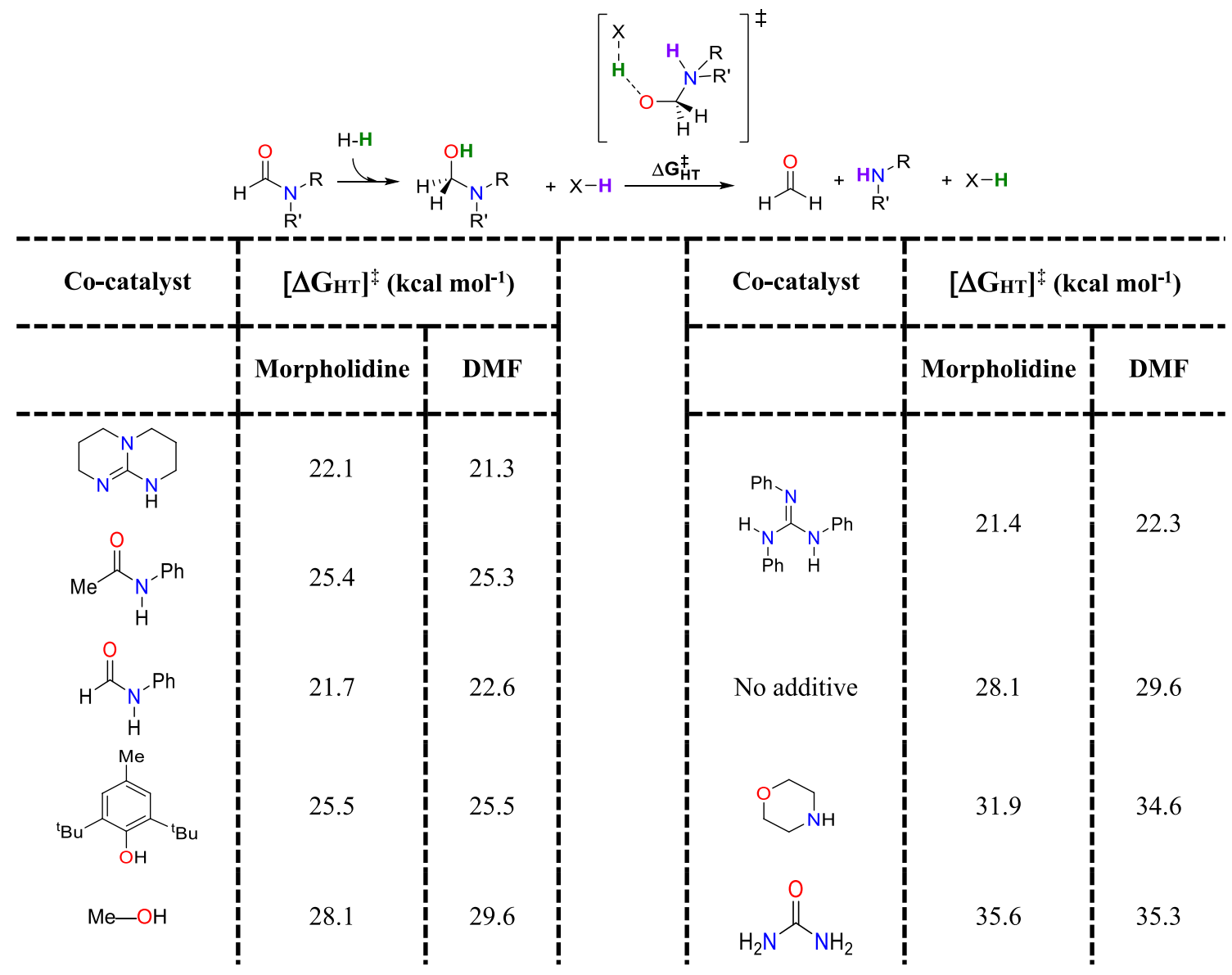

Fig. 16 Co-catalyst screening $[24,25]$. M06, 6-311+G** LANL2TZ, SMD $=$ THF, T=373.15 K, P=30 atm. Gibbs energies in kcal mol ${ }^{-1}$. Amide $+\mathrm{H}_{2}+$ co-catalyst $=0 \mathrm{kcal} \mathrm{mol}^{-1}$ 


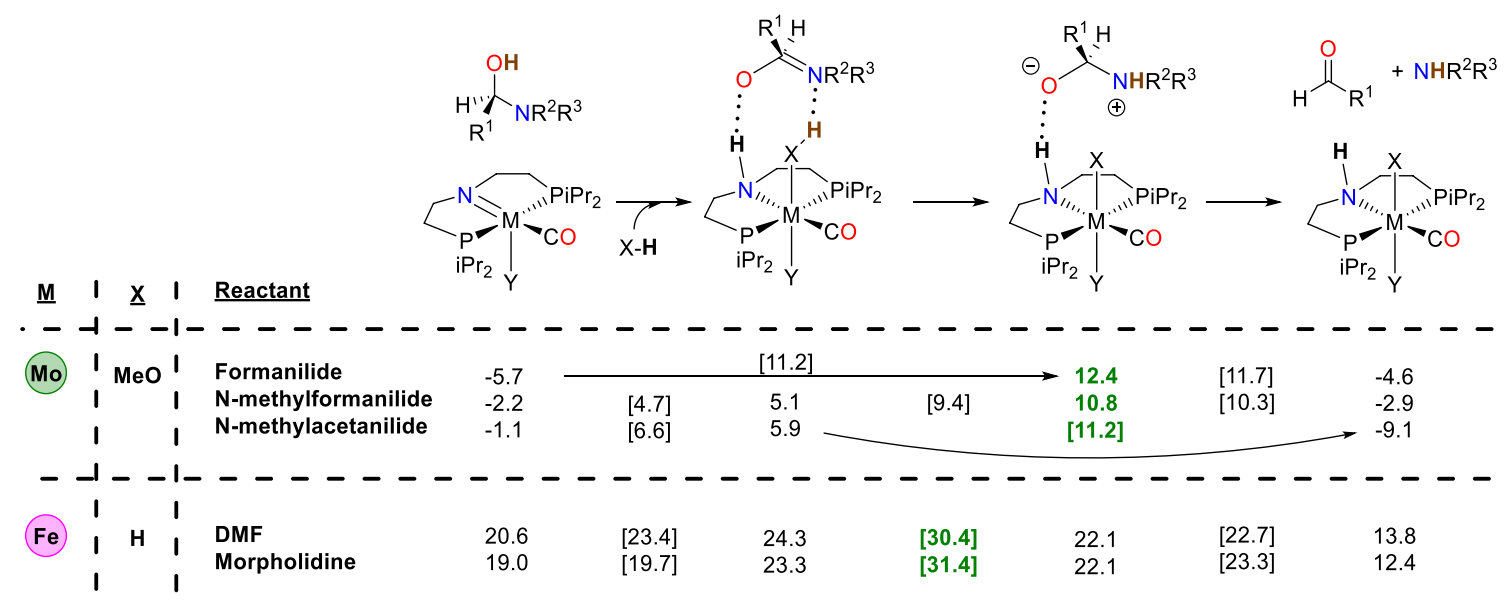

Fig. 17 Example of reaction mechanism of hemiaminal C-N protonolysis hydrogenations with Noyori-type catalysts and proton shuttle molecules. $\mathrm{Y}=\mathrm{CO}$ for $\mathrm{M}=\mathrm{Mo}$. $\mathrm{Y}=\mathrm{H}$ for $\mathrm{M}=\mathrm{Fe}$. Method: M06,
6-311 + G** LANL2TZ, SMD $=$ THF, $\mathrm{T}=373.15 \mathrm{~K}, \mathrm{P}=30$ atm $[24$, $26,27]$. Gibbs energies in kcal mol ${ }^{-1}$. Amide+hydrogenated catalyst + proton shuttle $=0 \mathrm{kcal} \mathrm{mol}^{-1}$ hydrogenation of DMF and morpholidine with iron Noyoritype catalysts when in the absence of methanol [24].

\section{Reaction Mechanisms for Aldehyde C=0 Hydrogenation}

Aldehyde $\mathrm{C}=\mathrm{O}$ hydrogenation is the last step of amide hydrogenation to amines and alcohols, and it is also relevant in the hydrogenation of esters and carboxylic acids. The mechanism of this reaction has been thus studied for a large number of systems $[37,45]$. but only those articles focusing on the catalytic deaminative hydrogenation of amides were considered for this review. In all reported cases, aldehyde hydrogenation followed the same mechanism underlying the hydrogenation of the amide carbonyl. Therefore, the reaction energies are given in Figs. 5 and 6 to compare the two reactions [24, 29, 34]. The steps of the mechanism are hydride transfer from the catalyst metal centre to the carbonyl carbon, followed by proton transfer from the catalyst ligand to the oxygen. All reported aldehyde $\mathrm{C}=\mathrm{O}$ hydrogenations are exergonic, and their transition states are thermally accessible and considerably lower in energy than those of the amides.

\section{Catalyst Hydrogenation and Catalyst Inhibition}

The hydrogenation of amides $\mathrm{C}=\mathrm{O}$ and $\mathrm{C}-\mathrm{N}$ or aldehyde $\mathrm{C}=\mathrm{O}$ groups with non-innocent bifunctional catalysts must be followed by a catalyst hydrogenation reaction. Milsteinand Noyori-type catalysts can heterolytically break a hydrogen molecule into a hydride and a proton which will be stabilized by the aromatization or protonation of the ligand (see Figs. 18 and 20). Unfortunately, the dehydrogenated form of these catalysts leaves their active site vulnerable to the attack of weak acids, which can deactivate them (see Figs. 18, 19, and 20). The most common weak acids present in the deaminative hydrogenation of amides are primary and secondary amides and alcohols, which are the reaction reactants and products, respectively. Two significant factors dictate the degree of catalyst inhibition: (1) the thermodynamic stability of the inhibited species with respect to the hydrogenated one, and (2) the concentration of hydrogen in solution with respect to the concentration of the inhibiting molecule, which will decrease during the course of the reaction in the case of alcohols, or increase in the case of primary and secondary amides. The latter factor forces the use of time-course simulations for the correct interpretation of these complex reaction mechanisms (see Sect. 7).

Many studies reported hydrogenation energies of Noyoritype bifunctional catalysts. For deaminative amide hydrogenations, in 2018 and 2019, our group reported the hydrogenation Gibbs energies of Fe and Mo Noyori-type catalysts, which were exergonic ( -10.2 and $-1.7 \mathrm{kcal} \mathrm{mol}^{-1}$, respectively; see Fig. 18) [26, 27]. Also in 2019, Pathak and co-workers reported the hydrogenation Gibbs energies of $\mathrm{Mn}-, \mathrm{Ru}-$ and Fe-based catalysts, which were also exergonic $\left(-1.1,-5.4\right.$ and $-5.4 \mathrm{kcal} \mathrm{mol}^{-1}$, respectively; see Fig. 18).

The effect of alcohols over Fe and Mo Noyori-type catalysts was studied by our group in 2019 and 2020 (see Fig. 18) [25, 26]. The dehydrogenated Fe catalyst could react with a methanol molecule and form an adduct $3.3 \mathrm{kcal} \mathrm{mol}^{-1}$ more energetic than the hydrogenated catalyst. This energy difference, despite endergonic, cannot be ignored at the end of the reaction when alcohol concentrations can be more than 5500 times that of the catalyst [40]. Our study also 


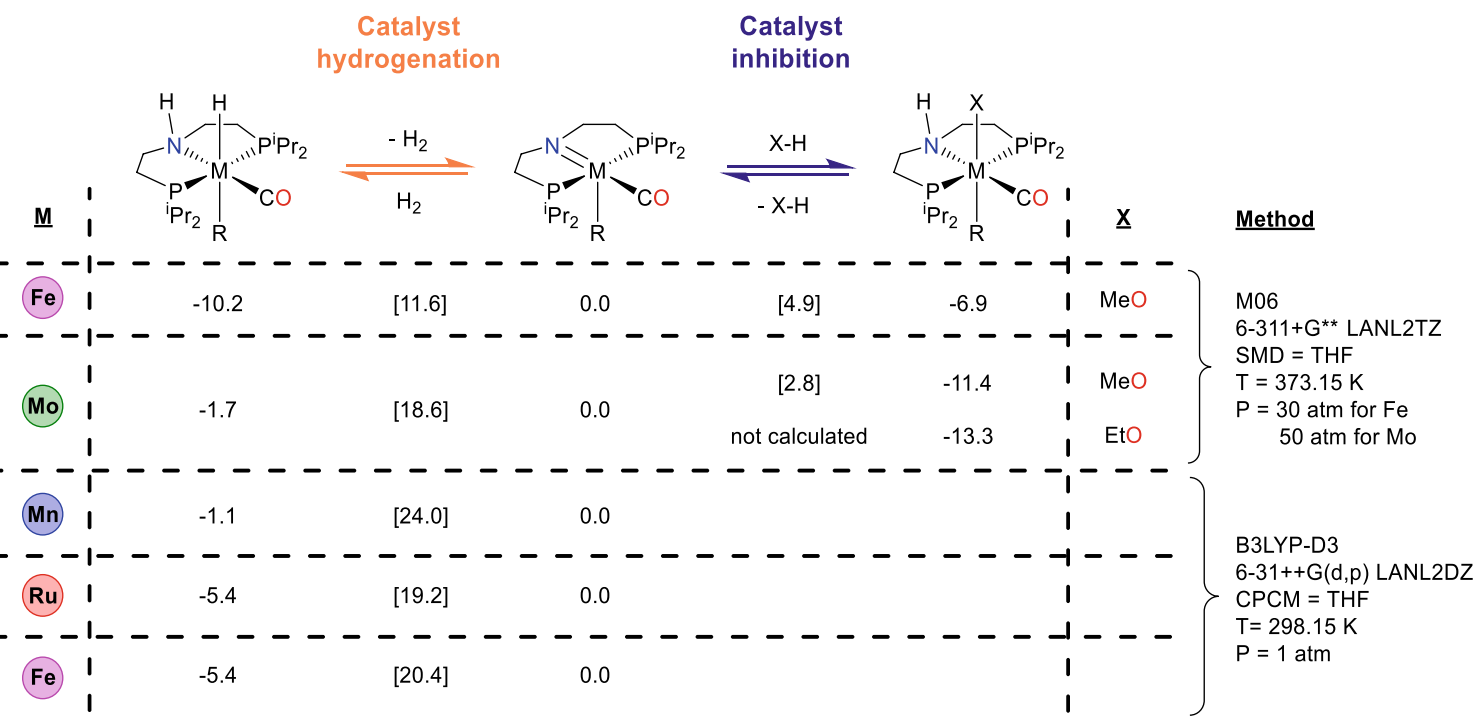

Fig. 18 Examples of Noyori-type catalyst hydrogenation and inhibition by alcohols [24, 26, 27, 34]. $\mathrm{R}=\mathrm{CO}$ for $\mathrm{M}=\mathrm{Mo}$ and $\mathrm{Mn}$. $\mathrm{R}=\mathrm{H}$ for $\mathrm{Fe}$ and Ru. Gibbs energies in $\mathrm{kcal} \mathrm{mol}^{-1}$

Fig. 19 Thermodynamic Gibbs energies $\left(\mathrm{kcal} \mathrm{mol}^{-1}\right)$ of $\mathrm{Fe}$ Noyori-type catalyst inhibition compared to catalyst hydrogenation $[24,25]$. Dehydrogenated catalyst + inhibitor $=0 \mathrm{kcal} \mathrm{mol}^{-1}$

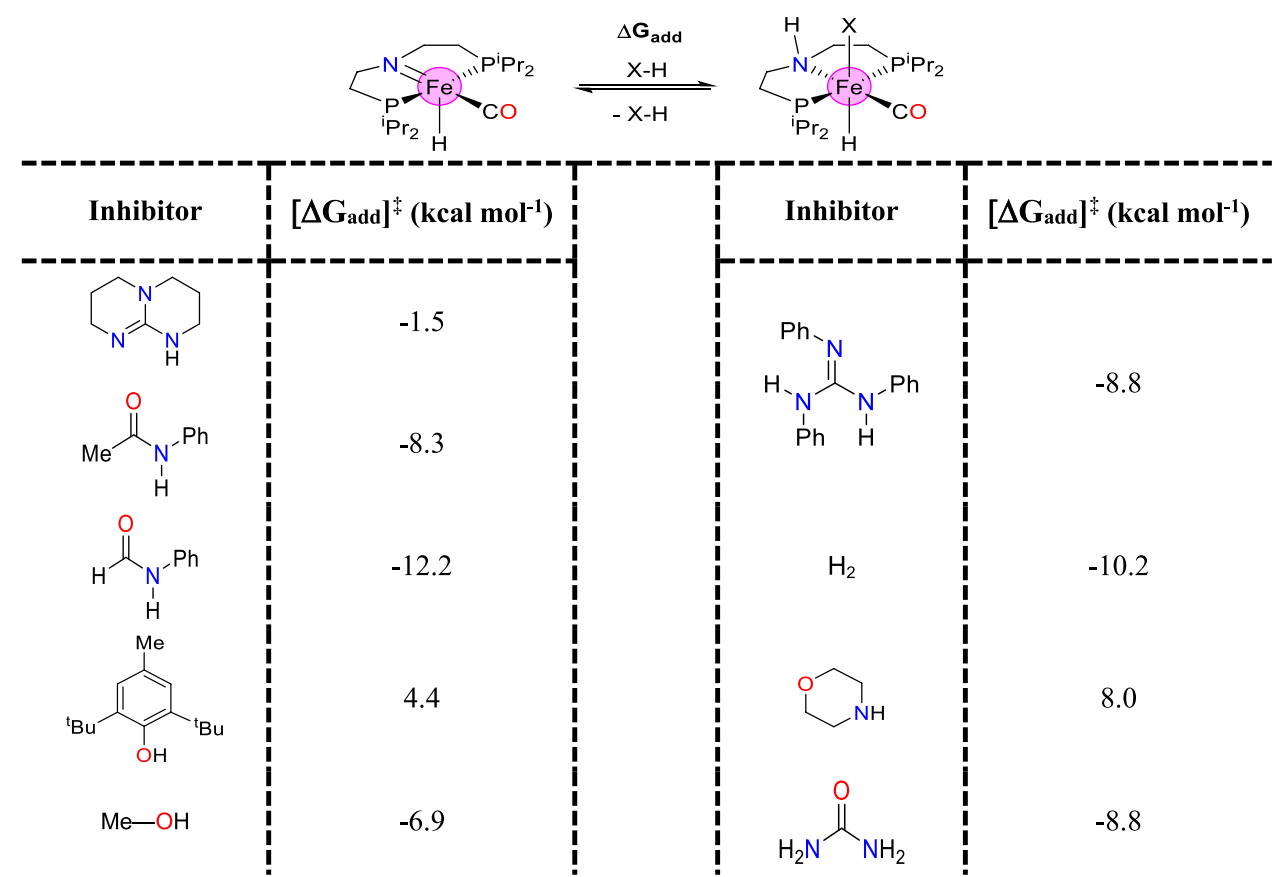

evaluated the inhibiting effect of other weak acid molecules to identify potential proton shuttle molecules that did not lead to catalyst poisoning (see Figs. 16 and 19) [24, 26]. The calculations predicted that the best performing species was TBD and acetanilide, due to an optimal balance between low energy barriers for proton transfer (see Fig. 16) and the moderate stability of their adducts with the dehydrogenated form of the catalyst (see Fig. 19). This prediction was later confirmed experimentally with $\mathrm{Fe}$ and $\mathrm{Ru}$-based Noyori-type catalysts [26]. On the other hand, the Mo catalyst showed a higher oxophilicity than that of the Fe catalyst, to the point where the high stability of the methanol and ethanol adducts inhibited the hydrogenation of acetamides (see Fig. 18).

Turning our attention to Milstein-type catalysts, four different ligands have been used for amide hydrogenation: three with tridentate ligands (C, B and D) [29, 30, 36], and one with a carbene ligand (see Fig. 20) [35]. The hydrogenation with ligand $\mathbf{C}$ is almost thermoneutral with an energy barrier of $28.5 \mathrm{kcal} \mathrm{mol}^{-1}$, whereas the hydrogenation reaction using the carbene ligand is irreversible $\left(-32.6 \mathrm{kcal} \mathrm{mol}^{-1}\right)$ 


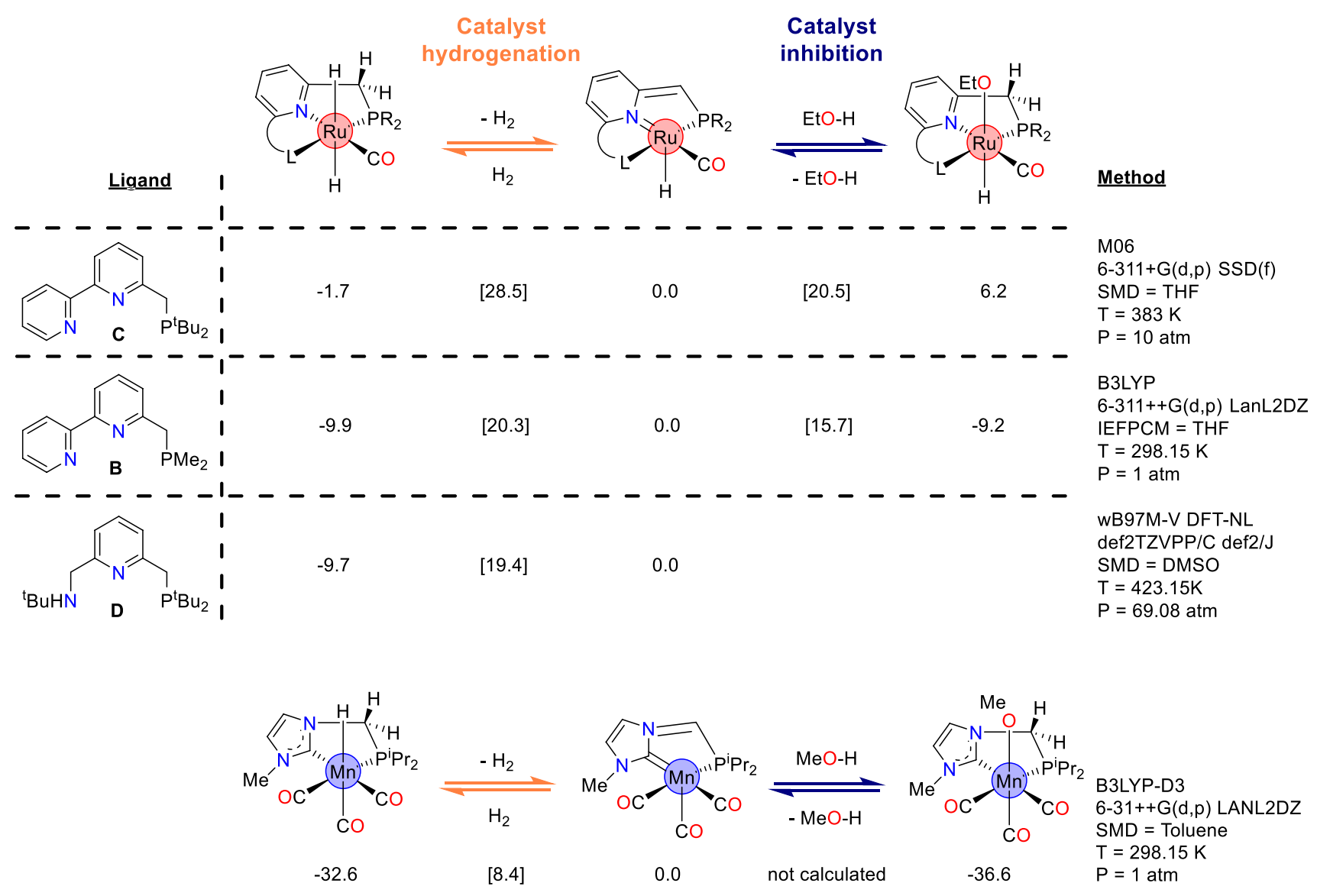

Fig. 20 Examples of Milstein-type catalyst hydrogenation and inhibition by alcohols [29, 30, 35, 36]. Gibbs energies in kcal mol ${ }^{-1}$

and has a low energy barrier of $8.4 \mathrm{kcal} \mathrm{mol}^{-1}$. Catalyst inhibition by alcohols has also been studied with $\mathrm{Ru}$ and carbene-based Mn systems, and was found to be endergonic for ligand $\mathbf{C}$ and exergonic for ligand $\mathbf{B}$ and the carbene-Mn system.

\section{Microkinetic Modelling}

The interpretation of the mechanisms for the deaminative hydrogenation of amides is not straight forward. The reasons are multiple: (1) several reaction mechanisms are possible and they can bifurcate and join, thus making their behavior correlated; (2) the catalyst inhibitors are not external species but rather reactants and products with concentrations evolving during the course of the reaction; (3) the concentration of hydrogen in solution along the reaction is not trivial to simulate because it depends on its solubility in each solvent and the hydrogen pressure.

Our studies have addressed points (1) and (2) with the use of microkinetic models that simultaneously consider all possible reaction pathways to construct and solve the reaction kinetics ordinary differential equations [24-27]. After setting initial reactants concentrations and reaction conditions, microkinetic models provide a prediction of the time-evolution of each reactant, intermediate and product. Upon comparison with experimental reaction yields, microkinetic models can be used to determine the most relevant mechanisms, which may change during the reaction, and evaluate the accuracy of the calculated energies [46]. Point (3) was addressed by using the concentration of $\mathrm{H}_{2}$ measured in pure THF at the pressure and temperature used experimentally and keeping it constant.

Sensitivity analysis were performed over our microkinetic models to find out the minima and transition states determining the reaction rate. Then, the amide conversions predicted by our models were compared against the experimental values. Finally, the energies of the determining minima and TSs were fitted to obtain the experimental conversions. The main conclusions provided by these analysis were the following: (1) the reaction mechanisms investigated by our group that involved $\mathrm{Fe}$ - and Mo-based Noyori-type catalysts had 3 and $2 \mathrm{kcal} \mathrm{mol}^{-1}$ energy errors, respectively; (2) high concentrations of secondary amides or alcohols promote proton shuttle mechanisms despite the high energy of the associated 
reaction pathways; (3) the effect of TBD over the deaminative hydrogenation of morpholidine with $\mathrm{Fe}$-based catalysts can be predicted with a deviation of only $3 \%$ relative to the experimental yield; (4) alcohols may have a positive and negative influence on product formation rates depending on their concentration. The later observation was found with a Mo-catalyst, in which the alcohol assists the hemiaminal proton transfer but inhibits the catalyst (Figs. 17 and 18).

\section{Summary and Outlook}

DFT calculations and mixed experimental-theoretical studies have made a major contribution towards a deeper understanding of the mechanisms underlying the catalytic reactions $[48,49]$. Deaminative hydrogenation of amides has not been an exception. For the amide $\mathrm{C}=\mathrm{O}$ hydrogenation, these studies have shown that there should be an interplay between the ligand and the metal centre promoting the pre-activation of hydrogen. Once $\mathrm{H}_{2}$ is cleaved, the hydride and proton transfer steps often take place through similar barriers. The structure of the amide is one of the main factors defining which of the two steps is the rate-determining. In general, these mechanisms do not involve a direct coordination of the substrate to the metal centre and are thus regarded as outer-sphere. In the Milsten-type catalysts, the substituents of the pyridine ring can have a strong impact on the energy profile, including the hydride transfer barrier. Interestingly, when the Milstein and Noyori moieties are combined within a single catalyst structure, the latter can dominate the reaction mechanism. In contrast with the carbonyl bond, the hydrogenation of the amide $\mathrm{C}-\mathrm{N}$ bond can follow innersphere mechanisms though this alternative pathway involves higher-energy profiles.

For the $\mathrm{C}-\mathrm{N}$ bond protonolysis of the hemiaminal intermediate, computational studies showed that the reaction can be assisted by the metal catalyst, by a proton shuttle molecule, or by both. The preference for one or the other mechanism depends on the substrate (nitrogen substituents) and the catalyst (metal centre and ligands). The catalyst-assisted mechanism, in which the ligand deprotonates the $\mathrm{OH}$ group, has two variants, depending on whether the nitrogen or the oxygen of the hemiaminal coordinates to the metal centre. In contrast, the proton shuttle-assisted mechanism can involve an amide acting as a co-catalyst, which facilitates the intramolecular proton transfer from the oxygen to the nitrogen of the hemiaminal. The amide can be added as a co-catalyst but can also play this role being the reactant. The alcohol product can also behave as a co-catalyst though, in general, it is less efficient at lowering the energy barriers. The hydrogenation of the aldehyde formed by protonolysis follows the same mechanism as that of the amide carbonyl.
The hydrogenation of the catalyst is exergonic in most cases, both in Noyori and Milstein systems. This reaction involves the heterolytic cleavage of the $\mathrm{H}-\mathrm{H}$ bond into a hydride and a proton that are stabilized by the metal centre and the ligand, respectively. Interestingly, computational studies have shown that the dehydrogenated form of the catalyst can also react with weak acids transferring the proton to the ligand. The resulting conjugated base is stabilized by coordinating to the metal centre forming an adduct. The weak acids yielding these adducts can be the reactants and products (i.e. amides and alcohols). The adducts can be significantly more stable that the dehydrogenated form of the catalyst and thus poison the latter. Due to the subtle energy differences between the different forms of the catalyst, the complexity of the mechanism (i.e. a network of competing pathways), and the time-evolution of all species involved, the full understanding of the catalytic deaminative hydrogenation of amides often requires microkinetic models. The development of new catalysts achieving higher yields under milder conditions thus requires considering all these variables.

Funding Open access funding provided by University of Oslo (incl Oslo University Hospital).

\section{Declarations}

Conflict of interest The authors have no conflicts of interest.

Disclaimer Ll.A.S., D.B., and A.N. acknowledge the support from the Research Council of Norway through its FRINATEK (No. 314321) and Centre of Excellence schemes (No. 262695). Ll.A.S. and A.N. acknowledge support from the "Nordic Consortium for CO2 Conversion" (NordForsk project No. 85378, site.uit.no/nordco2).

Open Access This article is licensed under a Creative Commons Attribution 4.0 International License, which permits use, sharing, adaptation, distribution and reproduction in any medium or format, as long as you give appropriate credit to the original author(s) and the source, provide a link to the Creative Commons licence, and indicate if changes were made. The images or other third party material in this article are included in the article's Creative Commons licence, unless indicated otherwise in a credit line to the material. If material is not included in the article's Creative Commons licence and your intended use is not permitted by statutory regulation or exceeds the permitted use, you will need to obtain permission directly from the copyright holder. To view a copy of this licence, visit http://creativecommons.org/licenses/by/4.0/.

\section{References}

1. Pattabiraman VR, Bode JW (2011) Rethinking amide bond synthesis. Nature 480:471-479. https://doi.org/10.1038/nature10702

2. De Figueiredo RM, Suppo JS, Campagne JM (2016) Nonclassical routes for amide bond formation. Chem Rev 116:12029-12122. https://doi.org/10.1021/acs.chemrev.6b00237 
3. Acosta-Guzmán P, Mateus-Gómez A, Gamba-Sánchez D (2018) Direct transamidation reactions: mechanism and recent advances. Molecules 23:2382. https://doi.org/10.3390/molecules23092382

4. Valeur E, Bradley M (2009) Amide bond formation: beyond the myth of coupling reagents. Chem Soc Rev 38:606-631. https:// doi.org/10.1039/b701677h

5. Mahesh S, Tang KC, Raj M (2018) Amide bond activation of biological molecules. Molecules 23:2615-2658. https://doi.org/ $10.3390 /$ molecules 23102615

6. Arthur G (2000) The amide linkage: selected structural aspects in chemistry, biochemistry, and materials science, 1st edn. WileyInterscience, Hoboken

7. Kar S, Goeppert A, Kothandaraman J, Prakash GKS (2017) Manganese-catalyzed sequential hydrogenation of $\mathrm{CO} 2$ to methanol via formamide. ACS Catal 7:6347-6351. https://doi.org/ 10.1021/acscatal.7b02066

8. Kothandaraman J, Goeppert A, Czaun M, Olah GA, Prakash GKS (2016) Conversion of $\mathrm{CO}_{2}$ from air into methanol using a polyamine and a homogeneous ruthenium catalyst. J Am Chem Soc 138:778-781. https://doi.org/10.1021/jacs.5b12354

9. Rezayee NM, Huff CA, Sanford MS (2015) Tandem amine and ruthenium-catalyzed hydrogenation of $\mathrm{CO}_{2}$ to methanol. J Am Chem Soc 137:1028-1031. https://doi.org/10.1021/ja511329m

10. Kar S, Kothandaraman J, Goeppert A, Prakash GKS (2018) Advances in catalytic homogeneous hydrogenation of carbon dioxide to methanol. J CO2 Util 23:212-218. https://doi.org/ 10.1016/j.jcou.2017.10.023

11. Smith AM, Whyman R (2014) Review of methods for the catalytic hydrogenation of carboxAMIDES. Chem Rev 114:54775510. https://doi.org/10.1021/cr400609m

12. Di Gioia ML, Belsito EL, Leggio A, Leotta V, Romio E, Siciliano C, Liguori A (2015) Reduction of amide carbonyl group and formation of modified amino acids and dipeptides. Tetrahedron Lett 56:2062-2066. https://doi.org/10.1016/j.tetlet.2015.02.074

13. Nystrom RF, Brown WG (1948) Reduction of organic compounds by lithium aluminum hydride. III. Halides, quinones, miscellaneous nitrogen compounds. J Am Chem Soc 70:37383740. https://doi.org/10.1021/ja01191a057

14. Weygand F, Eberhardt G, Linden H, Schäfer F, Eigen I (1962) Darstellung von Aldehyden Aus Carbonsauren. Angew Chem 53:525-531. https://doi.org/10.1016/0009-2509(62)87032-8

15. Kilner M, Tyers DV, Crabtree SP, Wood MA (2003) WO 03/093208 A1

16. Balaraman E, Gnanaprakasam B, Shimon LJW, Milstein D (2010) Direct hydrogenation of amides to alcohols and amines under mild conditions. J Am Chem Soc 132:16756-16758. https://doi.org/10.1002/chin.201116025

17. Cabrero-Antonino JR, Adam R, Papa V, Beller M (2020) Homogeneous and heterogeneous catalytic reduction of amides and related compounds using molecular hydrogen. Nat Commun 11:1-18. https://doi.org/10.1038/s41467-020-17588-5

18. Chardon A, Morisset E, Rouden J, Blanchet J (2018) Recent advances in amide reductions. Synthesis (Stuttg) 65:984-997. https://doi.org/10.1055/s-0036-1589144

19. Dub PA, Gordon JC (2017) Metal-ligand bifunctional catalysis: the "Accepted" mechanism, the issue of concertedness, and the function of the ligand in catalytic cycles involving hydrogen atoms. ACS Catal 7:6635-6655. https://doi.org/10.1021/acsca tal.7b01791

20. Dub PA, Gordon JC (2018) The role of the metal-bound N-H functionality in Noyori-type molecular catalysts. Nat Rev Chem 2:396-408. https://doi.org/10.1038/s41570-018-0049-z

21. Zell T, Langer R (2018) From ruthenium to iron and manganese-a mechanistic view on challenges and design principles of base-metal hydrogenation catalysts. ChemCatChem 10:19301940. https://doi.org/10.1002/cctc. 201701722
22. Filonenko GA, Van Putten R, Hensen EJM, Pidko EA (2018) Catalytic (de)hydrogenation promoted by non-precious metals$\mathrm{Co}, \mathrm{Fe}$ and $\mathrm{Mn}$ : recent advances in an emerging field. Chem Soc Rev 47:1459-1483. https://doi.org/10.1039/c7cs00334j

23. Alig L, Fritz M, Schneider S (2018) First-row transition metal (de)hydrogenation catalysis based on functional pincer ligands. Chem Rev 119:2681-2751. https://doi.org/10.1021/acs.chemr ev. 8 b00555

24. Artús Suàrez L (2021) Computational study on the deaminative hydrogenation of amides catalyzed by base metal complexes, PhD Dissertation, University of Oslo, Oslo

25. Artús Suàrez L, Jayarathne U, Balcells D, Bernskoetter WH, Hazari N, Jaraiz M, Nova A (2020) Rational selection of Cocatalysts for the deaminative hydrogenation of amides. Chem Sci 11:2225-2230. https://doi.org/10.1039/C9SC03812D

26. Leischner T, Artús Suàrez L, Spannenberg A, Junge K, Nova A, Beller M (2019) Highly selective hydrogenation of amides catalysed by a molybdenum pincer complex: scope and mechanism. Chem Sci 10:10566-10576. https://doi.org/10.1039/c9sc03453f

27. Artús Suàrez L, Culakova Z, Balcells D, Bernskoetter WH, Eisenstein O, Goldberg KI, Hazari N, Tilset M, Nova A (2018) The key role of the hemiaminal intermediate in the iron-catalyzed deaminative hydrogenation of amides. ACS Catal 8:8751-8762. https:// doi.org/10.1021/acscatal.8b02184

28. Piccirilli L, Pinheiro DLJ, Nielsen M (2020) Recent progress with pincer transition metal catalysts for sustainability. Catalysts 10:1-115. https://doi.org/10.3390/catal10070773

29. Zhang H (2015) A DFT study on direct hydrogenation of amide catalyzed by a PNN Ru(II) pincer complex. Comput Theor Chem 1066:1-6. https://doi.org/10.1016/j.comptc.2015.05.002

30. Cantillo D (2011) Mechanistic insights on the ruthenium-catalyzed hydrogenation of amides -C-N vs C-O cleavage. Eur J Inorg Chem. https://doi.org/10.1002/ejic.201100443

31. Inner-sphere mechanisms were proposed in the first computational studies but thereafter excluded when compared with outer-sphere mechanisms yielding lower-energy pathways.

32. Dobereiner GE, Nova A, Schley ND, Hazari N, Miller SJ, Eisenstein O, Crabtree RH (2011) Iridium-catalyzed hydrogenation of $\mathrm{N}$-heterocyclic compounds under mild conditions by an outersphere pathway. J Am Chem Soc 133:7547-7562

33. Hasanayn F, Harb H (2014) A metathesis model for the dehydrogenative coupling of amines with alcohols and esters into carboxamides by milsteins $[\mathrm{Ru}(\mathrm{PNN})(\mathrm{CO})(\mathrm{H})]$ catalysts. Inorg Chem 53:8334-8349. https://doi.org/10.1021/ic500743u

34. Mandal SC, Rawat KS, Nandi S, Pathak B (2019) Theoretical insights into $\mathrm{CO} 2$ hydrogenation to methanol by a Mn-PNP complex. Catal Sci Technol 9:1867-1878. https://doi.org/10.1039/ C9CY00114J

35. Das A, Mandal SC, Pathak B (2021) Unraveling the catalytically preferential pathway between the direct and indirect hydrogenation of $\mathrm{CO}_{2}$ to $\mathrm{CH}_{3} \mathrm{OH}$ using N-heterocyclic carbene-based $\mathrm{Mn}(\mathrm{i})$ catalysts: a theoretical approach. Catal Sci Technol 11:1375-1385. https://doi.org/10.1039/d0cy02064h

36. Kumar A, Von Wolff N, Rauch M, Zou YQ, Shmul G, Ben-David Y, Leitus G, Avram L, Milstein D (2020) Hydrogenative DEPOLYMERIZATION OF NYLONS. J Am Chem Soc 142:1426714275. https://doi.org/10.1021/jacs.0c05675

37. Qu S, Dai H, Dang Y, Song C, Wang Z-XX, Guan H (2014) Computational mechanistic study of Fe-catalyzed hydrogenation of esters to alcohols: improving catalysis by accelerating precatalyst activation with a Lewis base. ACS Catal 4:4377-4388. https://doi. org/10.1021/cs501089h

38. Chakraborty S, Lagaditis PO, Förster M, Bielinski EA, Hazari N, Holthausen MC, Jones WD, Schneider S (2014) Well-defined iron catalysts for the acceptorless reversible 
dehydrogenation-hydrogenation of alcohols and ketones. ACS Catal 4:3994-4003. https://doi.org/10.1021/cs5009656

39. Chen X, Jing Y, Yang X (2016) Unexpected direct hydride transfer mechanism for the hydrogenation of ethyl acetate to ethanol catalyzed by SNS Pincer ruthenium complexes. Chemistry A 22:1950-1957. https://doi.org/10.1002/chem.201504058

40. Jayarathne U, Zhang Y, Hazari N, Bernskoetter WH (2017) Selective iron-catalyzed deaminative hydrogenation of amides. Organometallics 36:409-416. https://doi.org/10.1021/acs.organomet. $6 \mathrm{~b} 00816$

41. Lane EM, Uttley KB, Hazari N, Bernskoetter W (2017) Ironcatalyzed amide formation from the dehydrogenative coupling of alcohols and secondary amines. Organometallics 36:2020-2025. https://doi.org/10.1021/acs.organomet.7b00258

42. Nguyen DH, Trivelli X, Capet F, Paul JF, Dumeignil F, Gauvin RM (2017) Manganese pincer complexes for the base-free, acceptorless dehydrogenative coupling of alcohols to esters: development, scope, and understanding. ACS Catal 7:2022-2032. https:// doi.org/10.1021/acscatal.6b03554

43. Bielinski EA, Förster M, Zhang Y, Bernskoetter WH, Hazari $\mathrm{N}$, Holthausen MC (2015) Base-free methanol dehydrogenation using a pincer-supported iron compound and Lewis acid co-catalyst. ACS Catal 5:2404-2415. https://doi.org/10.1021/acscatal. 5 b00137

44. Rezayee NM, Samblanet DC, Sanford MS (2016) Iron-catalyzed hydrogenation of amides to alcohols and amines. ACS Catal 6:6377-6383. https://doi.org/10.1021/acscatal.6b01454
45. Werkmeister S, Junge K, Wendt B, Alberico E, Jiao H, Baumann W, Junge H, Gallou F, Beller M (2014) Hydrogenation of esters to alcohols with a well-defined iron complex. Angew Chem Int Ed 33:8722-8726. https://doi.org/10.1002/anie.201402542

46. Besora M, Maseras F (2018) Microkinetic modeling in homogeneous catalysis. Wiley Interdiscip Rev Comput Mol Sci 8:1372. https://doi.org/10.1002/wcms.1372

47. Brunner E (1985) Solubility of hydrogen in 10 organic solvents at 298.15, 323.15, and 373.15 K. J Chem Eng Data 30:269-273. https://doi.org/10.1021/je00041a010

48. Lledós A (2021) Computational organometallic catalysis: where we are, where we are going. Eur J Inorg Chem 2021:2547-2555. https://doi.org/10.1002/ejic.202100330

49. Eisenstein O, Ujaque G, Lledós A (2020) What makes a good (computed) energy profile? In: Topics in Organometallic Chemistry. Springer, Cham, pp 67, 1-38

Publisher's Note Springer Nature remains neutral with regard to jurisdictional claims in published maps and institutional affiliations. 